\title{
Framework da qualidade da informação
}

\author{
Information Quality Framework
}

\begin{abstract}
Nadi Helena Presser Doutora em Engenharia de Produção. Universidade Federal de Pernambuco (UFPE) - Brasil. nadihelena@uol.com.br
Eli Lopes da Silva Doutor em Educação. Faculdade Senac Florianópolis (Senac/SC) - Brasil. eli.dasilva@prof.sc.senac.br
\end{abstract}

As organizações investem cada vez mais em tecnologia e recursos humanos para coletar, armazenar e processar grandes quantidades de dados. Mesmo assim, elas geralmente se veem frustradas em seus esforços para traduzir esses dados em informações relevantes que possam ser usadas para melhorar os processos de negócios, tomar decisões inteligentes e criar vantagens estratégicas. As questões que envolvem a qualidade dos dados e das informações e que causam essas dificuldades variam em natureza, desde a técnica (por exemplo, a integração de dados de fontes diferentes) até a não técnica (por exemplo, a falta de uma estratégia coesa, garantindo que os stakeholders e as pessoas em toda a organização tenham as informações corretas no formato certo, no local e na hora certos). Em outras palavras, a principal questão é ter a informação dizendo quais são as coisas certas a fazer aqui e agora (LILLRANK, 2003).

Vários estudos indicam que informações duvidosas, perdidas, atrasadas, incompletas ou ausentes são percebidas como um problema de qualidade muito sério, (ENGLISH, 1999; FERGUSON; LIM, 2001; CRUMP, 2002; LILLRANK, 2003). Huang, Lee e Wang (1999) enfatizam que a informação não deve ser tratada como um mero subproduto de várias atividades, mas com a mesma seriedade que os produtos. De acordo com Talburt (2011), a qualidade da informação é uma prática preocupada em maximizar o valor dos ativos de informação de uma entidade para garantir que os produtos de informação criados por ela atendam às expectativas dos clientes que os utilizam. Segundo o autor, em uma economia da informação, ela é um ativo estratégico e a qualidade da informação é uma vantagem competitiva.

A informação mobilizadora, com valor prático, que leva à ação, é aqui definida, corroborando com Lillrank (2003), como significado derivado de dados e do contexto, com uma função de criar conhecimento. Nessa abordagem, os dados representam o conteúdo factual, real e concreto da informação. Por exemplo, para informar o lucro líquido de uma empresa, sabemos que é calculado seguindo os procedimentos contábeis aceitos. Sendo assim, para fins práticos, é uma representação padronizada no campo das Ciências Contábeis. Com essa vinculação contextual, ao número (dado) é atribuído um significado, ao que denominamos informação. Agregamos valor à informação à medida que adicionamos mais informações contextuais a partir da demonstração contábil (lucro líquido), tais como: porcentagem de vendas, lucro líquido do período anterior, participação do lucro por produto. Logo, a qualidade da informação depende da qualidade dos dados (seu conteúdo) e, de modo igual, do conhecimento sobre as particularidades contábeis e do negócio que definem o contexto da empresa. Seguindo essa abordagem, a informação inclui, necessariamente, dados e contexto.

De acordo com Talburt (2011), nos anos 1990, muitas empresas, principalmente americanas, estavam convencidas de que coletar todos os seus dados em um único repositório criaria a informação estratégica que lhes daria uma vantagem competitiva. Era uma ideia convincente e conceitualmente correta, mas difícil de executar. Contudo, de acordo com o autor, a investida de reunir e armazenar dados foi o início da jornada para a qualidade das informações. Antes de tentar colocar os dados todos juntos, as organizações não tinham ideia de como eram inconsistentes, imprecisos, incompletos e mal organizados os dados em toda a empresa. E, se os dados formam o conteúdo factual, real e concreto da informação como sustenta Lillrank (2003), somente dados com qualidade produzirão informações de qualidade para alimentar processos decisórios de qualidade, adaptados às necessidades do negócio. Segundo English (1999), dar qualidade à informação é atender às expectativas dos clientes por meio de serviços e produtos de informação que lhes permitam realizar suas atividades efetivamente.

Para que as decisões sejam acertadas, as informações devem ter algumas propriedades que caracterizam sua qualidade. Como um produto físico que apresenta aspectos de qualidade, tais como facilidade de uso, material usado, propriedades de design, durabilidade etc., informações consideradas como produto também apresentam alguns 
aspectos de qualidade. Esses aspectos denominamos de dimensões ou critérios da qualidade da informação (HUANG; LEE; WANG, 1999).

A importância dos critérios da qualidade da informação pode mudar de acordo com a decisão. Portanto, podese dizer que os critérios têm classificações diferentes no âmbito de cada setor ou tipo de negócio. Huang, Lee e Wang (1999) produziram uma lista, definindo 15 dimensões (ou critérios) de qualidade da informação agrupadas em quatro categorias, como se lê no Quadro 1. Para esses autores, a qualidade da informação é definida como "a informação relevante para uso dos consumidores de informações." (HUANG; LEE; WANG, 1999, p. 43).

Quadro 1 - Categorias e dimensões da qualidade da informação

\begin{tabular}{|c|c|}
\hline Qualidade intrínseca & Qualidade da acessibilidade \\
\hline $\begin{array}{c}\text { Precisão } \\
\text { Objetividade } \\
\text { Credibilidade } \\
\text { Refutação } \\
\end{array}$ & $\begin{array}{c}\text { Acesso } \\
\text { Segurança }\end{array}$ \\
\hline Qualidade contextual & Qualidade representacional \\
\hline $\begin{array}{c}\text { Relevância } \\
\text { Valor agregado } \\
\text { Tempestividade } \\
\text { Completude } \\
\text { Quantidade de dados }\end{array}$ & $\begin{array}{l}\text { Interpretabilidade } \\
\text { Facilidade de compreensão } \\
\text { Representação concisa } \\
\text { Representação consistente }\end{array}$ \\
\hline
\end{tabular}

Fonte: Adaptado de Huang, Lee e Wang (1999).

Em sua análise, Huang, Lee e Wang (1999) observam que a escolha dos critérios de avaliação da qualidade da informação pode ser baseada em entendimento intuitivo, experiência profissional, revisão de literatura ou entrevistas com consumidores. Eles também concluem que não há acordo geral sobre as dimensões da qualidade da informação.

Eppler e Wittig (2000) argumentam que apresentar lista simples de critérios de qualidade da informação sem insights conceituais e sem fornecer orientação sistemática ou potencial de solução de problemas pode, em alguns casos, apresentar vantagens, mas também muitas desvantagens. Por exemplo, considere-se o trade-off entre disseminação e exatidão: quanto mais atual uma informação tiver que ser, menos tempo estará disponível para se verificar sua precisão. O mesmo trade-off vale para os critérios de integridade e pontualidade da informação: quanto mais rápida deve ser a entrega das informações ao usuário final, menos tempo estará disponível para se verificar sua confiabilidade ou integridade.

Portanto, seguindo os argumentos de Eppler e Wittig (2000), precisamos ir além das simples listas de critérios de qualidade da informação. Porter (1991 apud EPPLER; WITTIG, 2000) vê nos frameworks uma maneira legítima de construção de teoria e prática abrangentes para lidar com essas questões. Frameworksidentificam as variáveis relevantes e as perguntas que o usuário deve responder para desenvolver conclusões personalizadas para um setor e empresa em particular." (PORTER, 1991, p. 98 apud EPPLER; WITTIG, 2000, p. 85).

De acordo com Porter (1991), há uma pergunta fundamental relativa à abordagem para a construção da teoria que avançará tanto no conhecimento quanto na prática. As alternativas amplas estão representadas na Figura 1.

Figura 1 - Abordagem à construção da teoria

\section{MODELS $\longleftrightarrow$ FRAMEWORKS}

Fonte: Porter (1991, p. 97).

Por um lado, de acordo com Porter (1991), pode-se abordar a tarefa de desenvolver uma teoria (da estratégia ou da qualidade da informação, ou no campo da estratégia) criando uma ampla variedade de modelos de situações específicas, porém rigorosos (leia-se matemáticos), porém de complexidade limitada. Cada modelo abstrai a 
complexidade da competição (no caso da teoria da estratégia) para isolar algumas variáveis-chave, cujas interações são examinadas em profundidade. O significado normativo de cada modelo depende do ajuste entre suas suposições e a realidade. Nenhum modelo incorpora ou mesmo aborda todas as variáveis de interesse e, portanto, a aplicabilidade das descobertas de qualquer modelo é quase inevitavelmente restrita a um pequeno subgrupo de empresas ou setores cujas características se encaixam nas premissas do modelo.

Esses modelos, na melhor das hipóteses, fornecem informações sobre situações complexas que são difíceis de entender fora delas, o que pode orientar a análise da situação de uma empresa em particular, pondera Porter (1991). Considerando o objetivo de instruir a prática, o estilo de pesquisa no campo da estratégia, incluindo a qualidade da informação, demanda uma abordagem diferente. Em vez de modelos, é necessário criar frameworks.

A teoria incorporada nos frameworksé circunscrita na escolha das variáveis incluídas, na maneira como as variáveis são organizadas, nas interações entre as variáveis e na maneira como padrões alternativos de variáveis e escolhas da empresa afetam os resultados. (PORTER, 1991, p. 98).

Além disso, de acordo com Porter (1991), nem todas as interações entre as muitas variáveis nos frameworks podem ser rigorosamente desenhadas. Os frameworks, no entanto, procuram ajudar o analista a refletir melhor sobre o problema, entendendo a empresa e seu ambiente, definindo e selecionando entre as alternativas estratégicas disponíveis, independentemente do setor ou da empresa em análise.

As duas abordagens (modelos e frameworks) para a construção da teoria não são mutuamente exclusivas. De fato, elas deveriam criar uma tensão construtiva uma com a outra (PORTER, 1991). Os modelos são particularmente valiosos para garantir consistência lógica e explorar as interações sutis que envolvem um número limitado de variáveis. E uma vez que a construção de frameworks seja baseada em pesquisas empíricas aprofundadas, ela tem o potencial de não apenas instruir a prática, mas também impulsionar o desenvolvimento de uma teoria mais rigorosa.

Um framework de qualidade da informação, na opinião de Eppler e Wittig (2000), deve atingir quatro objetivos:

I. Fornecer um conjunto sistemático e conciso de critérios segundo os quais as informações possam ser avaliadas.

II. Fornecer um esquema para analisar e resolver problemas de qualidade da informação.

III. Fornecer a base para a medição da qualidade da informação e o gerenciamento continuado e proativo.

IV. Fornecer à comunidade de pesquisa um mapa conceitual que possa ser usado para estruturar uma variedade de abordagens, teorias e fenômenos relacionados à qualidade da informação.

Eppler e Wittig (2000) apontam as principais questões por trás de todos os metacritérios (conjuntos de critérios) de frameworks de qualidade da informação:

a. Se todos os critérios individuais de qualidade da informação, e se todas as categorias nas quais os critérios individuais estão agrupados (se existentes), estão definidas e explicadas.

b. Se o contexto de aplicação do framework (e seus limites) está claro, e se o framework está posicionado na literatura existente.

c. Se os critérios individuais são mutuamente exclusivos e coletivamente exaustivos. Se o frameworkgeral está dividido em categorias sistemáticas que também são mutuamente exclusivas e coletivamente exaustivas e se está claro por que um grupo de critérios pertence à mesma categoria.

d. Se são apresentados exemplos ilustrativos e específicos para elucidar os vários critérios.

e. Se o framework é acompanhado de um método, técnicas e ferramentas que podem ser usados para colocá-lo em prática (tais como um questionário, um aplicativo ou um guia de implementação passo a passo).

Eppler e Wittig (2000) avaliaram sete frameworks apresentados em publicações científicas que refletem o campo diverso da pesquisa em qualidade da informação. O resultado do estudo apontou que:

a. A maioria dos frameworks é específico para o contexto, em vez de genérico e amplamente aplicável;

b. Os frameworks não lidam explicitamente com distribuição e interdependências entre critérios individuais de qualidade da informação.

c. A maioria dos frameworks avaliados carece de métodos, técnicas e ferramentas de apoio que possibilitem colocá-los em prática.

Para concluir, corroboramos com Eppler e Wittig (2000) para destacar a magnitude e a premência de pesquisas dirigidas ao desenvolvimento de frameworks de qualidade da informação. A má qualidade das informações pode ter impactos sociais e econômicos substanciais. Embora as empresas estejam melhorando a qualidade dos dados e das 
informações com abordagens, métodos e técnicas práticas, seus esforços de melhoria não podem se concentrar estritamente no critério precisão.

Um framework captura dimensões da qualidade da informação que são importantes para os consumidores de informação. A qualidade da informação contextual destaca o requisito de qualidade dentro do contexto da tarefa em questão. A acessibilidade é um critério de qualidade da informação que enfatiza a importância do papel dos sistemas informatizados, da organização e da representação da informação.

Essas questões são consistentes com o princípio de que informações de qualidade devem ser contextualmente apropriados para a tarefa, claramente representadas e acessíveis ao consumidor. Usando frameworks, os gerentes de informação conseguem entender e atender às necessidades de qualidade da informação de seus consumidores de produtos ou serviços de informação.

\section{REFERÊNCIAS}

CRUMP, N. Managing professional integration in an acute hospital: a socio-political analysis. The International Journal of Public Sector Management, United Kingdom, v. 15, n. 2, p. 107-17, 2002.

ENGLISH, L. Improving data warehouse and business information quality. New York: Wiley \& Sons, 1999.

EPPLER, M. J.; WITTIG, D. Conceptualizing information quality: A review of information quality frameworks from the last ten years. In: CONFERENCE ON INFORMATION QUALITY - ICIQ, 5., 2000. Proceedings [...]. Switzerland: University of St Gallen, Switzerland, 2000.

FERGUSON, B.; LIM, J. N. W. Incentives and clinical governance: money following quality? Journal of Management in Medicine, United Kingdom, v. 15, p. 453-487, 2001.

HUANG, K.-T.; LEE, Y. W.; WANG, R. Y. Quality information and knowledge. Prentice-Hall: New York, 1999.

LILLRANK, P. The quality of information. International Journal of Quality and Reliability Management, v. 20, p. 691703, 2003.

PORTER, M.E. Towards a dynamic theory of strategy. Strategic Management Journal, United States, v. 12, p. 95-117, 1991.

TALBURT, J. Using information quality for competitive advantage. In: INTERNATIONAL SYMPOSIUM ON INFORMATION SYSTEMS AND MANAGEMENT - ISMAP, 2011. Proceedings [...]. Xi'an, China: Association for information systems, 2011. p. 9-11. 